\title{
Introduction to the Special Issue on COST Action FA1001
}

\author{
António A. Vicente ${ }^{1} \cdot$ Gerhard Schleining $^{2} \cdot$ Laura Piazza $^{3}$
}

Published online: 24 October 2015

(C) Springer Science+Business Media New York 2015

COST is the longest-running European framework supporting trans-national cooperation among researchers, engineers and scholars across Europe. It is a unique means for them to jointly develop their own ideas and new initiatives across all fields in science and technology, including social sciences and humanities, through panEuropean networking of nationally funded research activities.

In this context, COST Action FA1001 explored the "Application of innovative fundamental food-structureproperty relationships to the design of foods for health, wellness and pleasure."

Food industry is constantly challenged to meet consumer demands for new food products that are safe, convenient, affordable, pleasurable and healthy. An understanding of fundamental structure-function relationships of food components is a key to the design of new foods. Ingredient formulation and production processes have a major role in commercial food development, but their impact on food structure is poorly characterized. Furthermore the influence of structure and physical properties on nutritional and health-inducing properties of foods (e.g., bioavailability/efficacy of nutrients/bioactives) has

António A. Vicente

avicente@deb.uminho.pt

1 Centre for Biological Engineering, Universidade do Minho, Campus de Gualtar, 4710-057 Braga, Portugal

2 Department of Food Science and Technology Food Physics Laboratory, University of Natural Resources and Life Sciences Vienna, Muthgasse 18, 1190 Vienna, Austria

3 Department of Food, Environmental and Nutritional Sciences, University of Milan, Via Mangiagalli, 25, 20133 Milan, Italy received little attention from the scientific community. This action created an interdisciplinary team to apply the fundamental structure-properties knowledge of multiphasefoods (foams, emulsions) to real food systems, with a view to designing end-products with good sensory quality and health benefits. The action resulted in an experts network able to bridge the gap between material scientists, food technologists and nutritionists.

This Special Issue gathers selected contributions from experts of the action on several aspects of food structure design explored throughout the action's activity, from basic science to applications and behavior of foods during digestion:

- Molecular dynamics and structure in physical properties and stability of food systems

- Designing food structure using microfluidics

- Encapsulation of functional lipophilic food and drug biocomponents

- Structuring food emulsions to improve nutrient delivery during digestion

- Trends in encapsulation technologies for delivery of food bioactive compounds

- Edible bio-based nanostructures: delivery, absorption and potential toxicity

People who are interested in these research topics are welcome to join the Special Interest Group on "Food Structure" of the ISEKI-Food Association (https://www. iseki-food.net/general/sigs/sig1) for free. This group will maintain the network of this COST action in order to organize trainings, exchange ideas and methodologies and organize further research activities. 